Journal of Animal

Ecology 2000,

69, 952-958

\title{
Silver spoons and snake body sizes: prey availability early in life influences long-term growth rates of free- ranging pythons
}

\author{
THOMAS MADSEN and RICHARD SHINE \\ Biological Sciences A08, University of Sydney, NSW 2006, Australia
}

\begin{abstract}
Summary
1. A 13-year study of free-ranging water pythons (Liasis fuscus) and their main prey (dusky rats, Rattus colletti) in tropical Australia provided extensive data on the relationship between python growth rates and prey availability.

2. Python growth rates exhibited considerable variation among individuals. Growth rates of siblings were not correlated, suggesting that environmental rather than genetic factors cause this wide variation.

3. The availability of prey varied considerably among years, due to annual variation in rainfall patterns. Pythons grew more rapidly in years with high rat abundance than in years when rats were scarce. Also, python cohorts that hatched in years when prey were abundant exhibited faster growth rates than those that hatched when prey were scarce.

4. The snakes showed strong ontogenetic consistency in relative growth rates: that is, an individual with faster-than-average growth in its first year of life continued to grow rapidly throughout the study period. Thus, these pythons displayed a strong 'silver spoon' effect, whereby favourable conditions (high prey abundance) in the first year of life exerted a long-term effect on growth trajectories and thus, adult body sizes. This effect was strongest in the faster-growing sex (females).

5. Hence, the current body size composition of the python population reflects stochastic rainfall-induced annual variation in prey availability over the preceding decades.
\end{abstract}

Key-words: environment, prey abundance, reptile, resources, snake

Journal of Animal Ecology (2000) 69, 952-958

\section{Introduction}

An animal's body size influences many aspects of its interaction with the environment; for example, body size may determine the animal's food habits, its vulnerability to predation, and its reproductive output (e.g. Mushinsky, Hebrard \& Vodopich 1982; Calder 1984; Reiss 1989). The rate at which the organism increases in size thus has profound implications for its biology, and patterns of growth constitute an important axis of variation among individuals, among populations, and among species. Clearly, growth rates are very flexible, and are influenced by intrinsic factors ('rules' by which ingested energy is allocated among the competing demands of metabo-

Correspondence: Professor Shine, Biological Sciences A08, University of Sydney, NSW 2006, Australia. Tel: 612-9351-3772, Fax: 61-2-9351-5609, E-mail: rics@bio.usyd. edu.au lism, storage, growth and reproduction) as well as by local resource availability (e.g. Andrews 1982; Lepage, Gauthier \& Reed 1998). Thus, an animal's growth trajectory is determined partly by its genes, and partly by the nutritional environment that it encounters.

One issue of particular interest is the possibility that food availability early in an organism's life can have a disproportionate effect on its later growth pattern and thus, eventual maximum body size. Such a 'silver-spoon effect' (Grafen 1988) might generate substantial size variation among cohorts, without any genetic underpinning. Given that body size is highly correlated with reproductive success in many organisms (e.g. Andersson 1994), such environmentally induced variation might generate much of the observed intrapopulational diversity in organismal fitness. Thus, the effect, if any, of food availability early in life warrants examination. 
Some kinds of organisms are more likely than others to modify their growth rates in response to fluctuations in prey availability. A primary dichotomy in this respect is the division between determinate growers, in which maximal body sizes are attained fairly early in life, and indeterminate growers, in which growth continues throughout life (albeit at a slower rate with increasing age/size). Most or all endothermic vertebrates display determinate growth; indeed, birds typically attain full adult size prior to fledging (Lack 1968). In contrast, many types of ectothermic animals exhibit indeterminate growth (e.g. Andrews 1982). This dichotomy has strong implications for the ways in which prey availability can influence growth trajectories. By definition, an increase in prey abundance that occurs late in the organism's life cannot modify body size in a determinate-grower, because that animal's body size has already been set, but could modify body size of an indeterminate-growth organism.

For endothermic animals such as birds, the traditional view has been that patterns of body size variation of adults reflect underlying genetic variation rather than environmentally induced plasticity in growth rates (e.g. Hamilton 1961; Zink \& Remsen 1986). However, this view has come under strong challenge in recent years. For example, in both barnacle geese (Branta leucopis) and snow geese (Chen caerulescens), food availability during the goslings' first weeks has a dramatic impact on their eventual adult body size (Cooch et al. 1991; Larsson \& Forslund 1991; Larsson et al. 1998; Lepage et al. 1998). However, we might expect that body sizes of indeterminate-growers are influenced by food availability throughout life, and hence that any 'silver spoon' effects are likely to be obliterated by subsequent levels of prey availability.

Large snakes may offer good model systems in this respect. They exhibit indeterminate growth through their (potentially long) life (Andrews 1982), and a single population of such species thus contains individuals of a very wide range of body sizes (e.g. Fitch 1999). In the present study we present data on growth of a large tropical snake, the water python (Liasis fuscus) and discuss how annual variation in prey availability affects individual, year-to-year variation in growth and ultimately adult snake body sizes.

\section{Materials and methods}

\section{STUDY AREA}

Our study was conducted in the Fogg Dam conservation reserve, in the lower reaches of the Adelaide River floodplain $60 \mathrm{~km}$ south-east of Darwin in the Northern Territory of Australia. The area lies within the 'wet-dry' tropics. Temperatures are high yearround (mean daily maximum air temperature $>30$
${ }^{\circ} \mathrm{C}$ in every month) but precipitation is concentrated in a brief (3-month) 'wet-season'; rainfall is highly variable among years (Taylor \& Tulloch 1985; Madsen \& Shine 1999a). The Adelaide River floodplain is a relatively flat, treeless area formed by silt deposition from the river. The floodplain is inundated by monsoonal rains each year.

\section{STUDY SPECIES}

Water pythons (Liasis fuscus Peters) are large (up to $3 \mathrm{~m}$ ) non-venomous snakes widely distributed across tropical Australia (Cogger 1992). The pythons in our study area feed almost exclusively on a small (up to $210 \mathrm{~g}$ ) species of native rodent, the dusky rat, Rattus colletti Thomas (Shine \& Madsen 1997; Madsen \& Shine 1998). These rats exhibit extreme annual variation in abundance, under the influence of stochastic annual variations in rainfall (Redhead 1979; Madsen \& Shine 1999a).

\section{METHODS FOR STUDYING PYTHONS}

Data were collected over the period from December 1986 to September 1998. Fieldwork was concentrated in the dry-season months of July to October each year, for logistical reasons. The pythons were caught at night by spotlighting (on foot, or from a slowly moving vehicle), and released the following day after they had been measured, weighed, sexed, and individually marked for later recognition. Our analyses in the present paper are based primarily on a subset of marked snakes for which we could confidently infer the age of each snake. The known-age snakes fall into two groups: (1) offspring from eggs that we hatched in captivity, so that we knew the exact date of hatching of all the offspring; and (2) hatchlings and juveniles that were collected in the field. The reproductive cycle of the pythons in our study area is highly synchronous. Mating occurs in July to early August, oviposition from mid September to early October, and hatching from mid November to early December (Madsen \& Shine 1996a). To calculate growth rates of juveniles captured in the field during their first year of life (when we could confidently infer their age from their small body size: SVLs $<110 \mathrm{~cm}$ ), we used mean values for captive-hatched offspring (1 December as hatching date, SVL of $45 \mathrm{~cm}$ ). The captive-hatched offspring were the progeny of 116 females collected while gravid (55 in 1991, 61 in 1992). We obtained 552 viable hatchlings in 1991, and 672 in 1992 (Madsen \& Shine 1996a). Offspring hatched in captivity were weighed, measured and scale-clipped $<24 \mathrm{~h}$ after hatching. All hatchlings were released a few days after hatching in a single area, $50 \mathrm{~m}$ north of Fogg Dam.
(C) 2000 British Ecological Society Journal of Animal Ecology, 69, 952-958 
954

Environmental

influences on

growth rates
METHODS FOR STUDYING RATS

The data used in the present study refer to trapping conducted in August from 1990 to 1998. Trapping during this period of the dry-season offers an index of rat abundance during the preceding wet-season, when predation rates by pythons are highest and when hatchling pythons commence feeding (Shine \& Madsen 1997). We used 50 Elliott traps placed at $10-\mathrm{m}$ intervals along a 500-m transect on the floodplain $6 \mathrm{~km}$ NE of Fogg Dam. The traps were checked at sunrise over a 5-day period (i.e. five nights' trapping). Traps were baited with rolled oats, and placed at the same positions during each year. Each rat was marked with an individually numbered ear tag and given a month-specific toeclip. We recorded trap number, mass, body length (tip of nose to anus) and sex for each captured rat. For further information concerning dusky rat demography, see Madsen \& Shine (1999a).

\section{Results}

\section{GENERAL GROWTH PATTERNS}

We have data on body sizes of 471 known-age snakes (268 males, 203 females) that were marked after hatching in captivity or captured as yearlings in the field. The young pythons grew rapidly for the first few years, before attaining asymptotic sizes of approximately $170 \mathrm{~cm}$ for males and about $190 \mathrm{~cm}$ for females (Fig. 1). Growth rates of females were faster than those of males, and females continued to grow at older ages (one-factor heterogeneity of slopes test with sex as factor, ln age as covariate and In SVL as dependent variable: $F_{1,1081}=94.8, P=$ 0.0001).

\section{INDIVIDUAL VARIATION IN GROWTH} RATES

Individual pythons varied considerably in the rates at which they grew, resulting in a wide range of

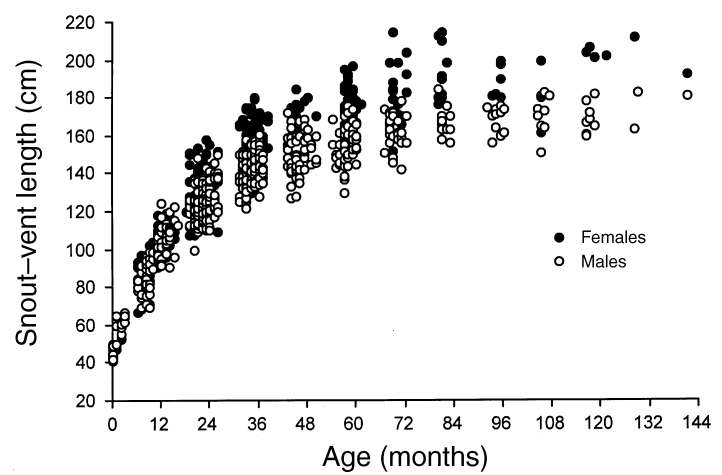

(C) 2000 British Ecological Society Journal of Animal Ecology, 69, 952-958
Fig. 1. Body sizes (snout-vent lengths, $\mathrm{cm}$ ) of known-age water pythons (Liasis fuscus) in relation to their age (months since hatching). body lengths for any given age. For example, some 2-year-old females were larger than some 9-year-old females (Fig. 1). Thus, age could not be inferred from body sizes for any snake $>110 \mathrm{~cm}$ SVL (i.e. after the first year of life). Measurements of body sizes of 21 male and 18 female pythons that were first marked at an age of 7-12 months and later recaptured on at least three occasions separated by long intervals (i.e. when they were about 2-year-old, 3-4-year-old and 6-12-year-old) revealed substantial variation in growth rates among individual male and female pythons (Fig. 2a,b). Pythons that were larger than average early in life remained larger than average (relative to other individuals of the same age) later in life (males: $r=0.58, P=0.006$, d.f. $=20 ; \quad$ females: $r=0.58, \quad P=0.011, \quad$ d.f. $=17$; based on residual scores from a linear regression of ln SVL vs. In age). Furthermore, the growth rates of these individual snakes during their first year of life were positively correlated with their growth rates later in life (males: $r=0.63, P=0.002$, d.f. $=20$; females: $r=0.70, P=0.0001$, d.f. $=17$; Fig. 3, based on residual scores from a linear regression of daily growth increment vs. SVL).

Of the 1224 hatchlings released in 1991 and 1992, siblings were recaptured from 26 different broods. Growth rates of these siblings were no more similar to each other than would be expected by chance (comparing pairs of siblings based on within-sex residual scores from the linear regression of $\ln \mathrm{SVL}$ vs. In age: $r=-0.30, P=0 \cdot 14$, d.f. $=25)$. Indeed, there was a tendency for a negative rather than posi-

(a)

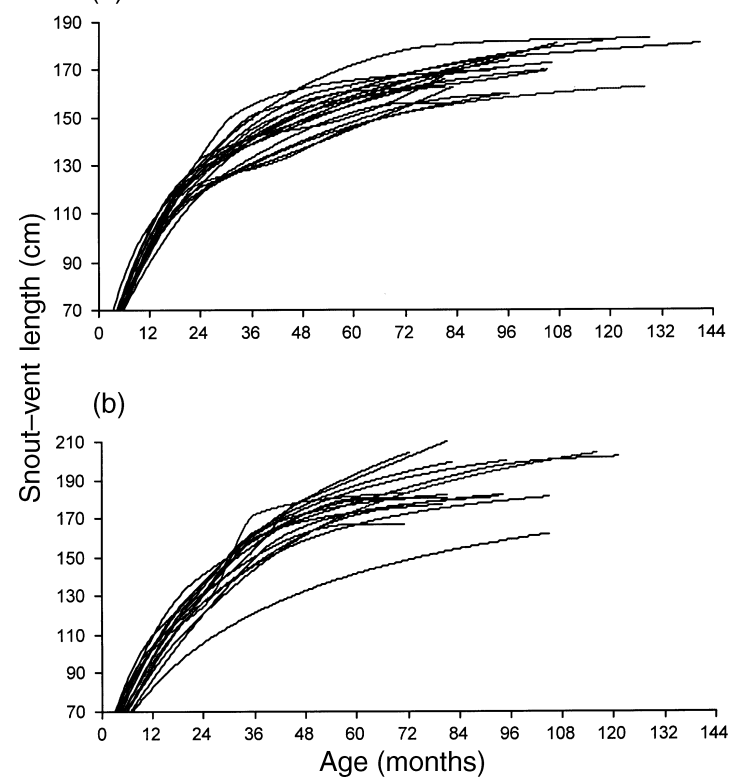

Fig. 2. Growth trajectories of individually marked water pythons (Liasis fuscus) over the first few years of life. Data for (a) males and (b) females. 
955

T. Madsen \& $R$. Shine

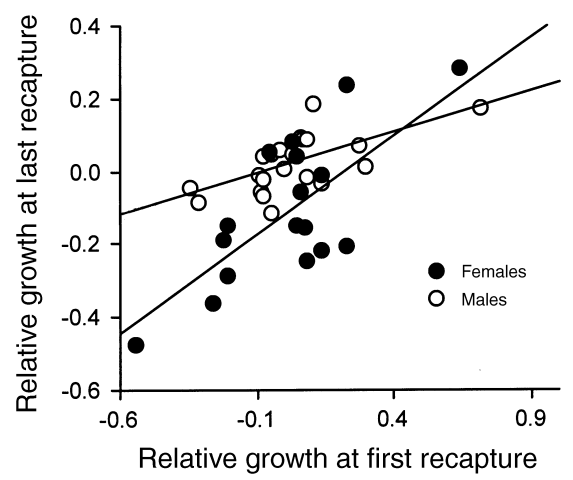

Fig. 3. Ontogenetic consistency in relative growth rates of water pythons (Liasis fuscus). For each axis, the 'relative growth' measure is the residual score from a linear regression of growth increment against midpoint of snout-vent length during the recapture interval. Snakes that grew slowly in their first year of life, also grew slowly (relative to other snakes) when recaptured later in life.

tive correlation between the growth rates of sibling snakes (Fig. 4). Thus, our data provide no evidence for genetic influences on individual variation in growth rates.

\section{EFFECT OF HATCHING YEAR ON GROWTH RATES}

Some annual cohorts displayed much faster growth rates (measured over the next several years) than did cohorts that hatched in other years (one-factor ANOVA with year of hatching as the factor: for differences among cohorts, $F_{12,1080}=11.23, P<0.001$, based on residual scores from linear regression of $\ln$

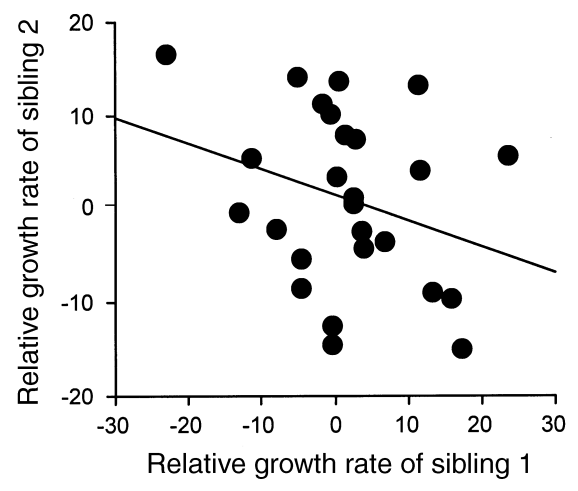

Fig. 4. Pairwise within-sex comparison of growth rates of sibling water pythons. The regression compares relative growth rate (residual score from the linear regression of growth rate to mean snout-vent length) of one snake to that of a sibling. Residual scores were calculated separately for males and females. Siblings were not more similar to each other in growth rates than would be expected by chance; indeed, they tended to be less similar. See text for statistical results.

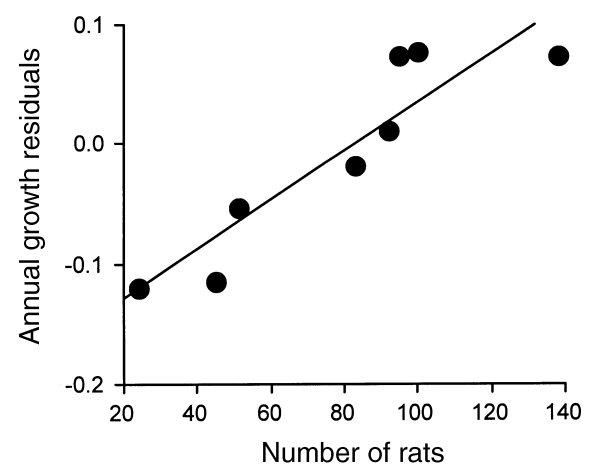

Fig. 5. Annual variation in relative growth rates of water pythons (as indexed by residual scores from the linear regression of growth rate to mean snout-vent length) relative to prey abundance (as indexed by the number of rats captured in our dry-season sampling) in the same year. Each point represents data from 1 year of our study.

SVL vs. In age). Linear regression revealed a significant correlation between prey abundance at the time of hatching and cohort growth rates throughout the rest of the study period (Fig. $5 ; r=0.89, P=0.0035$, d.f. $=7)$. Thus, we can characterize some cohorts as 'fast-growing' and colleagues as 'slow-growing' overall, not just in their first year of life.

\section{ANNUAL VARIATION IN GROWTH RATES}

Because this analysis does not require knowledge of the exact ages of individuals, we could use a much larger data set based on all snakes recaptured during subsequent years. A one-factor ANOVA with year as the factor confirms that snakes grew more rapidly in some years than in others $\left(F_{10,914}=7.53, P<\right.$ 0.0001; data from 1987-88 to 1997-98, based on residual scores from a linear regression of daily growth increment vs. SVL). A simple regression analysis supports the putative link between prey availability and snake growth rates: the pythons grew faster during years when the rats were more abundant (Fig. 6; $r=0.92, P=0.001$, d.f. $=7$ ).

\section{WHAT IS THE MAGNITUDE OF THE 'SILVER SPOON' EFFECT ON GROWTH RATES?}

The size of a snake relative to other pythons of the same age was influenced both by the year in which the snake first hatched $\left(F_{12,999}=5.79, P<0.0001\right)$ and by the year in which it was later captured (i.e. at the time that overall growth rate was measured: $F_{12,999}=5.19, P<0.0001$; two-factor ANOVA with age and growth rate as factors). The ANOVA also revealed a highly significant interaction between these two factors $\left(F_{12,999}=3.49, P<0.0001\right)$, suggesting that the way in which current prey availability influenced growth rates (see Fig. 5) was modified 


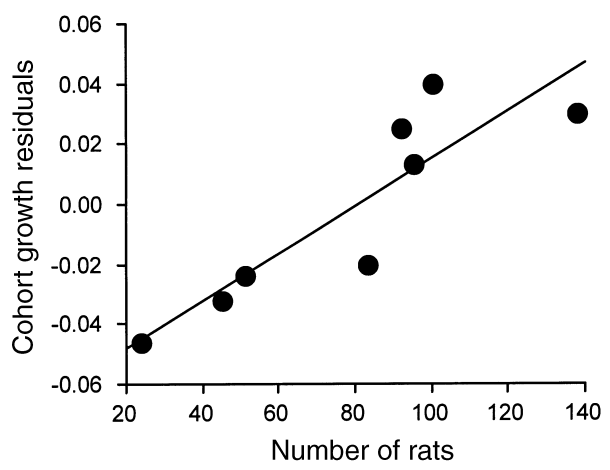

Fig. 6. Variation among annual cohorts of water pythons, relative to prey abundance in the year when the cohort hatched. Each point represents data from one annual cohort of pythons. Growth rates are based on residual scores from the linear regression of growth rate (increment in SVL) to mean snout-vent length, and include data from throughout the study (i.e. are based on recapture rates of old as well as young snakes). Prey abundance is measured as the number of rats captured during our dry-season sampling in the year in which each cohort hatched.

by the earlier effect of food supply during the snake's first year of life (see Fig. 6). Approximately $29 \%$ of the variation in growth rates among our marked pythons is attributable to 'silver spoon' effects (i.e. year of hatching), $25 \%$ to current prey availability (i.e. year in which growth was measured), and the remaining $46 \%$ to the interaction between prey availability at these two time-scales (calculated from mean squares in the ANOVA table, Sokal \& Rohlf 1981).

Because females grow larger than males (Fig. 1), we repeated the ANOVA above, incorporating sex as a factor. The results confirmed a strong effect of sex on age-specific size $\left(F_{1,946}=47.74, P<0.0001\right)$, but did not change our interpretation of the effects of annual variation. The magnitude of effects on growth rates due to year of hatching $\left(F_{12,946}=5 \cdot 28\right.$, $P<0.0001)$ and current year $\left(F_{12,946}=6.54, P<\right.$ $0.0001)$ remained similar to those derived from the two-factor analysis above. The three-factor ANOVA also revealed strong interactions between the effects of sex and year of hatching $\left(F_{11,946}=3.09, \quad P<\right.$ $0.0005)$ and between sex and current year $\left(F_{11,946}=\right.$ 3.42, $P<0.0001)$. That is, the effects of food availability on growth rate differed between the sexes, both for yearling snakes and for older animals. Thus, the magnitude of the 'silver spoon' effect differed between males and females. The faster-growing sex (females) was more sensitive to variation in food supply early in life (Fig. 3).

(C) 2000 British Ecological Society Journal of Animal Ecology, 69, 952-958

\section{Discussion}

The present study reinforces our previous conclusion that demographic processes within the python popu- lation at Fogg Dam are driven by prey availability (abundance of rats), which in turn is ultimately driven by annual variation in the timing and intensity of wet-season rainfall (Madsen \& Shine 1996a, b, 1998, 1999a, b, c; Shine \& Madsen 1997). In years with rainfall patterns that allow prolonged rat breeding, the resulting abundance of prey generated cohorts of young pythons with unusually rapid growth rates. Rat abundance also influenced the growth rates of older snakes, such that there was considerable annual variation in rates of growth among pythons of all sizes.

The lack of significant family level effects on growth rate suggests that growth rates (and thus, body sizes) of adult pythons may be influenced more by proximate factors than by genetic (or other maternal) influences. Growth rates were consistently linked to rat abundance, suggesting that variations in food supply drive variations in growth rate. This inference is supported by other field data (e.g. Bronikowski \& Arnold 1999) as well as by experimental studies that demonstrate the same link in captive snakes (e.g. Ford \& Seigel 1989; Seigel \& Ford 1991).

Similar links between food abundance and growth rate are widespread, although not universal. Under some conditions, growth rates may be determined by some factor other than food supply. For example, food may be superabundant (such that variation in prey abundance does not affect feeding rates) or else, feeding rates may be constrained by weather conditions (e.g. Heatwole 1962) or by the risks associated with foraging (e.g. Lima \& Dill 1990; Sinclair \& Arcese 1995; Lima 1998). Nonetheless, increases in food availability are consistently associated with increases in growth rates of the organisms using that food, for a very wide range of species and habitats, e.g. molluscs (Nakaoki \& Matsui 1994), fishes (Keller et al. 1990; Jorgensen 1992), frogs (Galatti 1992) and mammals (Bolton, Newsome \& Merchant 1982).

Our analyses show that contemporaneous levels of food supply influenced growth rates of pythons, but only to about the same degree as levels of food availability earlier in the individual's life. Thus, an animal's body size reflected not only its age, sex and current feeding rate, but was also a function of the nutritional environment that the animal experienced in the past. Importantly, the way that current levels of prey availability influenced current levels of growth was itself modified by the animal's early growth history. The end result is that the variation in growth rates that was engendered among cohorts of yearling pythons persisted throughout the life of the snakes. We do not know the mechanism by which this 'silver spoon' effect occurs, but our data show that the rate at which a python grows is determined not only by its current feeding rate, but also 
T. Madsen \& R. Shine

(C) 2000 British Ecological Society Journal of Animal Ecology, 69. 952-958 by the nutritional environment that it encountered in its first year of life.

Although similar effects of food supply early in life on growth trajectories of adult organisms are likely to be widespread, they have attracted little study under field conditions. Some of the best examples involve research on geese, where variation in forage quality drives variation in adult body size (Cooch et al. 1991; Larsson \& Forslund 1991; Larsson et al. 1998; Lepage et al. 1998). Despite the paucity of examples, we predict that 'silver spoon' effects will prove to be widespread. Early nutrition has important long-term effects on a diverse array of organisms ranging from domestic mammals and birds (e.g. Wilson \& Osbourn 1960; Sadleir 1969) to forest trees (Florence 1996). Such effects may operate in complex ways, depending on details of the timing, duration and magnitude of the changes in food availability (e.g. Wilson \& Osbourn 1960). Different age groups or sexes within the population may also respond differently. For example, in the case of water pythons the faster-growing sex (females) was more sensitive to early food deprivation than their slower-growing (male) equivalents.

These results have strong implications for attempts to interpret spatial and temporal variation in body sizes. Our study suggests that the distributions of body sizes reflect not only food availability at the present time, but a complex integration of levels of food availability over the lifetimes of all of the organisms present in the population. That is, two populations (in different places, or in the same place at different times) might differ substantially in mean size because of some prior event (e.g. a year of low food supply several years previously). This effect will be exacerbated if annual variation in food supply affects rates of recruitment, and thus the age distribution of the population (Madsen \& Shine 1998).

Other important life-history attributes may be subject to the same kind of influence of the 'memory' of past events. Because of their extraordinary plasticity, reptiles offer excellent examples in this respect. For example, adult female water pythons modify their body-condition threshold for breeding in response to relatively long-term levels of prey abundance, rather than food supply in the current year (Madsen \& Shine 1999c). Reproductive frequencies in many snakes reflect prey availability over a series of years prior to the present season (Bonnet \& Naulleau 1996). A female lizard's 'decision' about her litter size reflects her experience in previous years, as well as current food availability (Doughty \& Shine 1998). Operational sex ratios among adults in reptile species with temperaturedependent sex determination may reflect weather influences on nest temperatures over the preceding years (e.g. Bull 1980). In each of these cases, the current traits of organisms are modified by past events.
The 'silver spoon' effect is simply one example of this phenomenon.

More generally, our data on growth rates of freeranging pythons reinforce the hypothesis that many aspects of demography include substantial time lags, and hence that we may not be able to understand present-day aspects of population demography purely in the light of current conditions. Such phenomena are inaccessible to study in short-term projects, and provide yet more evidence that long-term field studies are essential if we are to fully appreciate the ways in which natural populations respond to variation in the biotic and abiotic environment.

\section{Acknowledgements}

We thank G. Bedford, B. Cantle, E. Cox, P. Fisher, P. Harlow, P. Osterkamp, J. Osterkamp and G. King-Brown for field assistance, and K. Levy for logistical support. E. Tasker pointed out the analogy with tree growth, and S. Downes, S. Broomhall and P. Borges gave comments on the manuscript. The study was funded by the Australian Research Council.

\section{References}

Andersson, M. (1994) Sexual Selection. Princeton University Press, Princeton, New Jersey.

Andrews, R.M. (1982) Patterns of growth in reptiles. Biology of the Reptilia, Vol. 13 (eds G. Gans \& F.H. Pough), pp. 273-320. Academic Press, New York.

Bolton, B.L., Newsome, A.E. \& Merchant, J. (1982) Reproduction in the agile wallaby, Macropus agilis (Gould), in the tropical lowlands of the Northern Territory: opportunism in a seasonal environment. Australian Journal of Ecology, 7, 261-277.

Bonnet, X. \& Naulleau, G. (1996) Catchability in snakes: consequences on breeding frequency estimates. Canadian Journal of Zoology, 74, 233-239.

Bronikowski, A.M. \& Arnold, S.J. (1999) The evolutionary ecology of life history variation in the garter snake Thamnophis elegans. Ecology, 80, 2314-1325.

Bull, J.J. (1980) Sex determination in reptiles. Quarterly Review of Biology, 55, 4-21.

Calder, W.A. (1984) Size, Function and Life History. Harvard University Press, Boston.

Cogger, H.G. (1992) Reptiles and Amphibians of Australia. 4th edn. Reed Books. Sydney.

Cooch, E.G., Lank, D.B., Dzubin, A., Rockwell, R.F. \& Cooke, F. (1991) Body size variation in lesser snow geese: environmental plasticity in gosling growth rates. Ecology, 72, 503-512.

Doughty, P.D. \& Shine, R. (1998) Energy allocation to reproduction in a viviparous lizard species (Eulamprus tympanum): the role of long-term energy stores. Ecology, 79, 1073-1083.

Fitch, H.S. (1999) A Kansas Snake Community: Composition and Changes Over 50 Years. Krieger Publishing Company, Malabar, Florida.

Florence, R.G. (1996) Ecology and Silviculture of Eucalypt Forests. CSIRO, Collingwood, Victoria. 
958

Environmental

influences on

growth rates
Ford, N.B. \& Seigel, R.A. (1989) Phenotypic plasticity in reproductive traits: evidence from a viviparous snake. Ecology, 70, 1768-1774.

Galatti, U. (1992) Population biology of the frog Leptodactylus pentadactylus in a central Amazonian rainforest. Journal of Herpetology, 26, 23-31.

Grafen, A. (1988) On the uses of data on lifetime reproductive success. Reproductive Success. Studies of Individual Variation in Contrasting Breeding Systems (ed. T.H. Clutton-Brock), pp. 454-471. University of Chicago Press, Chicago.

Hamilton, T.H. (1961) The adaptive significance of intraspecific trends of variation in wing length and body size among bird species. Evolution, 15, 180-195.

Heatwole, H. (1962) Environmental factors influencing local distribution and activity of the salamander, Plethodon cinereus. Ecology, 43, 460-472.

Jorgensen, T. (1992) Long-term changes in growth of Northeast Arctic cod (Gadus morhua) and some environmental influences. ICES Journal of Marine Science, 49, 263-277.

Keller, A.A., Doering, P.H., Kelly, S.P. \& Sullivan, B.K. (1990) Growth of juvenile Atlantic menhaden, Brevoortia tyrannus (Pisces: Clupeidae) in MERL mesocosms: effects of eutrophication. Limnology and Oceanography, 35, 109-122.

Lack, D. (1968) Ecological Adaptations for Breeding Birds. Methuen, London.

Larsson, K. \& Forslund, P. (1991) Environmental induced morphological variation in the Barnacle Goose, Branta leucopis. Journal of Evolutionary Biology, 4, 619-636.

Larsson, K., van der Jeugd, H.P., van der Veen, I.T. \& Forslund, P. (1998) Body size declines despite positive directional selection on heritable size traits in a barnacle goose population. Evolution, 52, 1169-1184

Lepage, D., Gauthier, G. \& Reed, A. (1998) Seasonal variation in growth of greater snow goose gosling: the role of food supply. Oecologia, 114, 226-235.

Lima, S.L. (1998) Nonlethal effects in the ecology of predator-prey interactions. Bioscience, 48, 25-34.

Lima, S.L. \& Dill, L.M. (1990) Behavioral decisions made under the risk of predation: a review and prospectus. Canadian Journal of Zoology, 68, 619-640.

Madsen, T. \& Shine, R. (1996a) Determinants of reproductive output in female water pythons (Liasis fuscus, Pythonidae). Herpetologica, 52, 146-159.

Madsen, T. \& Shine, R. (1996b) Seasonal migration of predators and prey: pythons and rats in tropical Australia. Ecology, 77, 149-156.

Madsen, T. \& Shine, R. (1998) Quantity or quality? Determinants of maternal reproductive success in tropical pythons (Liasis fuscus). Proceedings of the Royal Society, Series B, 265, 1521-1525.
Madsen, T. \& Shine, R. (1999a) Rainfall and rats: climatically-driven dynamics of a tropical rodent population. Australian Journal of Ecology, 24, 80-89.

Madsen, T. \& Shine, R. (1999b) Life-history consequences of nest-site variation in tropical pythons. Ecology, 80, 987-997.

Madsen, T. \& Shine, R. (1999c) The adjustment of reproductive threshold to prey abundance in a capital breeder. Journal of Animal Ecology, 68, 571-580.

Mushinsky, H.R., Hebrard, J.J. \& Vodopich, D.S. (1982) Ontogeny of water snake foraging ecology. Ecology, 63, 1624-1629.

Nakaoki, M. \& Matsui, S. (1994) Annual variation in the growth rate of Yoldia notabilis (Bivalvia: Nuculanidae) in Otsuchi Bay, northeastern Japan, analyzed using shell microgrowth patterns. Marine Biology (Berlin), 119, 397-404.

Redhead, T.D. (1979) On the demography of Rattus sordidus colletti in monsoonal Australia. Australian Journal of Ecology, 4, 115-136.

Reiss, M.J. (1989) The Allometry of Growth and Reproduction. Cambridge University Press, Cambridge.

Sadleir, R.M.F.S. (1969) The Ecology of Reproduction in Wild and Domestic Mammals. Methuen, London.

Seigel, R.A. \& Ford, N.B. (1991) Phenotypic plasticity in the reproductive characteristics of an oviparous snake, Elaphe guttata: implications for life history studies. Herpetologica, 47, 301-307.

Shine, R. \& Madsen, T. (1997) Prey abundance and predator reproduction: rats and pythons on a tropical Australian floodplain. Ecology, 78, 1078-1086.

Sinclair, A.R.E. \& Arcese, P. (1995) Population consequences of predation-sensitive foraging: the Serengeti wildebeest. Ecology, 76, 882-891.

Sokal, R.R. \& Rohlf, F.J. (1981). Biometry, 2nd edn. W.H Freeman, New York.

Taylor, J.A. \& Tulloch, D. (1985) Rainfall in the wet-dry tropics: extreme events at Darwin and similarities between years during the period 1870-1983. Australian Journal of Ecology, 10, 281-295.

Wilson, P.N. \& Osbourn, D.F. (1960) Compensatory growth after undernutrition in mammals and birds. Biological Review, 35, 324-363.

Zink, R.M. \& Remsen, J.V. Jr (1986) Evolutionary processes and patterns of geographical variation in birds. Current Ornithology, Vol. 4 (ed. R.F. Johnston), pp. 1-69. Plenum Press, New York.

Received 22 November 1999; revision received 24 May 2000
(C) 2000 British Ecological Society Journal of Animal Ecology, 69, 952-958 